\title{
Using the polymeric circulating tumor cell chip to capture circulating tumor cells in blood samples of patients with colorectal cancer
}

\author{
KAZUMASA KURE ${ }^{1}$, MASAKI HOSOYA ${ }^{1}$, TAKAE UEYAMA ${ }^{1}$, MIDORI FUKAYA ${ }^{1}$, KIICHI SUGIMOTO ${ }^{1}$, \\ YUICHI TOMIKI $^{1}$, TAKASHI OHNAGA ${ }^{2}$, KAZUHIRO SAKAMOTO ${ }^{1}$ and HIROMITSU KOMIYAMA ${ }^{1}$ \\ ${ }^{1}$ Department of Coloproctological Surgery, Juntendo University School of Medicine, Tokyo 113-8421; \\ ${ }^{2}$ Central Research Laboratories, Toyama Industrial Technology Center, Toyama 933-0981, Japan
}

Received December 18,2018; Accepted August 29, 2019

DOI: $10.3892 / \mathrm{ol} .2020 .11335$

\begin{abstract}
The current study clarified the accuracy of a circulating tumor cell (CTC) detection system to diagnose colorectal cancer using blood samples. The system uses the 'polymeric CTC-chip,' (CTC-chip), which is a microfluidic device that is used for CTC isolation. CTCs are considered sensitive diagnostic biomarkers. However, their concentration in the peripheral blood is low and requires highly sensitive and specific capturing techniques. The capture efficiency of the polymeric CTC-chip was first assessed using cell suspensions of the colorectal cancer cell line HCT-116, which was reported as $90.9 \%$ in a phosphate-buffered saline suspension and $65.0 \%$ in the blood. The CTC-chip was then used to detect CTCs in blood samples obtained from 13 patients with stage II-IV colorectal cancer. On average, the CTCs $/ \mathrm{ml}$ was lower in patients with stages II and III colorectal cancer (3.3 \pm 2.3$)$ than in those with stage IV (7.0 \pm 6.2$)$. In patients with stages II-IV, $92 \%$ had $\geq 1$ CTC per ml, which was significantly higher than the positive rate (15\%) detected using the carbohydrate antigen 19-9 test (CA19-9). Furthermore, CTCs were detected in all patients with stage II and III colorectal cancer, including a number of patients with negative results for the carcinoembryonic antigen (CEA) and CA19-9 tests. With the polymeric CTC-chip detection system, CTCs can be effective cancer markers, particularly for patients with stage II and III colorectal cancer who often exhibit negative conventional serum marker test results. The CTC-chip system may also facilitate the detection of cancer progression based on CTC concentration.
\end{abstract}

Correspondence to: Dr Hiromitsu Komiyama, Department of Coloproctological Surgery, Juntendo University School of Medicine, 2-1-1 Hongo, Bunkyo-Ku, Tokyo 113-8421, Japan

E-mail: hrkomiya@juntendo.ac.jp

Key words: circulating tumor cells, tumor biomarkers, colorectal cancer, microfluidic devices, cancer screening

\section{Introduction}

Colorectal cancer is the second most common cancer in women $(9.5 \%)$ and the third in men $(10.2 \%)$ and ranked as the second most common cause of cancer death (9.2\%) worldwide (1). Therefore, sensitive and noninvasive diagnoses are important to improve its treatment outcomes. However, conventionally used biomarkers in blood samples, such as carcinoembryonic antigen (CEA) and carbohydrate antigen 19-9 (CA19-9), do not always indicate the pathological aspects of malignancy (2).

The use of circulating tumor cells (CTCs) as the next-generation cancer marker has been an active research topic in the field of oncology for the past two decades (3-6). The peripheral blood CTC concentration is reported to be extremely low: $<10$ cells $/ \mathrm{ml}$ in patients with metastatic cancer $(3,7)$. However, CTCs are not present or scarcely detected in the blood of healthy individuals nor in those with nonmalignant diseases $(8,9)$. Nucleic acid evaluation in CTCs and direct enumeration of CTCs are typical methods used to detect CTCs requiring highly sensitive techniques. To evaluate nucleic acid levels in blood CTCs, related gene expressions are examined using reverse transcription-quantitative PCR (RT-qPCR), or DNA arrays (9-13). Cell capturing methods based on size or surface antibodies $(6,10)$, such as the CellSearch ${ }^{\mathrm{TM}}$ System (Veridex LLC) (CellSearch) and other microfluidic devices, are used for direct enumeration (14-16). CellSearch is a semi-automated system for CTC quantification as a diagnostic method for metastatic breast, colorectal, and prostate cancers approved by the US Food and Drug Administration (FDA) $(17,18)$. Moreover, the efficacy of this system has been reported in metastatic breast, prostate, esophageal, and colorectal cancers (19-25). However, the use of CellSearch is limited due to its high cost (26-28) and low sensitivity to some cancer types, such as hepatocellular carcinoma $(28,29)$. Approximately $18 \%$ of non-metastatic and $41 \%$ of metastatic patients with colon cancer are positive with CTCs in the CellSearch system (30).

Nagrath et al (15) developed a microfluidic device known as the 'CTC-chip' to overcome these limitations. The 'CTC-chip' facilitates efficient and selective separation of CTCs from whole blood samples, mediated by the interaction of target CTCs with antibody-coated microposts under precisely 
controlled laminar flow conditions $(15,31)$. Subsequently, a novel 'polymeric CTC-chip' was developed to isolate CTCs, with lower cost, high transparency that facilitates observation through the chip, and convertibility of antibodies to coat the surface to arrest cancer cells than that of the existing CTC-chips (32-36).

In the present study, the capture efficiency of the polymeric CTC-chip was measured using colorectal cancer cells spiked in phosphate-buffered saline (PBS) or healthy whole blood at first. Next, CTCs in clinical blood samples were detected in patients with colorectal cancer. The sensitivity of CTC detection in the blood samples of patients with colorectal cancer was compared with that of the CEA and CA19-9 tests.

\section{Materials and methods}

Preparation of cancer cells. HCT116 (ATCC ${ }^{\circledR}$ CCL-247 ${ }^{\mathrm{TM}}$ ) colorectal cancer cells were cultured and exhibited a high expression of epithelial cell-adhesion molecule (EpCAM), in McCoy's 5A medium (cat. no. 16600082; Invitrogen) with $10 \%$ fetal bovine serum and $1 \%$ penicillin-streptomycin at $37^{\circ} \mathrm{C}$ in a humidified $5 \% \mathrm{CO}_{2}$ atmosphere. Then, the EpCAM expression in HCT116 cells was evaluated with a flow cytometer (FACSVerse; BD Biosciences) using a PE/Cy7-conjugated anti-human CD326 (EpCAM) antibody (cat. no. 324221; BioLegend) and FlowJo software (ver.9; FlowJo LCC). To determine the EpCAM localization in the cells, Alexa Fluor ${ }^{\circledR}$ 594-conjugated anti-human CD326 (EpCAM) antibodies (cat. no. 324228; BioLegend) at $5 \mu \mathrm{g} / \mathrm{ml}$ was added to the HCT116 cell suspension; the mixture was allowed to sit for $2 \mathrm{~h}$ at room temperature and examined using a fluorescence microscope system (BZ-X710; Keyence) in a 24-well plastic dish (a cell culture plate with a lid; Sigma-Aldrich).

Preparation of cancer cell suspensions. To measure the capture efficiency, HCT116 cells were fluorescently labeled using the Cell Explorer ${ }^{\mathrm{TM}}$ Live Cell Tracking kit (cat. no. 22621; AAT Bioquest). The cells were spiked in PBS containing 5\% bovine serum albumin (BSA; PBS suspension) or the whole blood obtained from a healthy donor and stored in a vacuum blood collection tube containing ethylenediaminetetraacetic acid (EDTA; VP-DK052K; Terumo; blood suspension) at $4^{\circ} \mathrm{C}$. All cell suspensions were prepared at approximately 1,000 cells $/ \mathrm{ml}$ concentration, and the precise concentration of each suspension was determined.

Antibody coating on the chip surface. An antibody coating of the polymeric CTC-chip surface was determined using the method described by Ohnaga et al (32), with the process outline illustrated in Fig. 1. The chip was washed with $70 \%$ ethyl alcohol once for hydrophilization and then exposed to goat anti-mouse IgG antibodies overnight (cat. no. 1032-01; Southern Biotech) in PBS at a $25 \mu \mathrm{g} / \mathrm{ml}$ concentration at $4^{\circ} \mathrm{C}$. Then, the chip surface was washed with PBS once to remove any non-bonded anti-IgG antibodies and kept wet. Next, the chip surface was coated with mouse anti-human EpCAM antibodies (cat. no. sc-59906; Santa Cruz Biotechnology) in PBS at a $25 \mu \mathrm{g} / \mathrm{ml}$ concentration and stored at room temperature for $1 \mathrm{~h}$. The chip was washed with PBS again after the antibody treatment.
CTC capturing system and evaluation of the cell-capture efficiency. The sample flow and CTC capturing were performed using the method described by Ohnaga et al (32). The workflow of CTC detection with the polymeric CTC-chip is outlined in Fig. 2. Briefly, the polymeric CTC-chip coated with antibodies was set in a holder and fixed on an inverted fluorescence microscope stage (CKX41; Olympus). The size of the polymeric CTC-chip was $75 \times 25 \mathrm{~mm}$, and surface microstructures comprised two types of micropost arrays in a wide channel (32). The two ports of the holder were then connected to a syringe or sample tube with tubing and fittings, which allowed the liquid sample to flow through the channel (32). Then, the sample tube was shaken to prevent cell precipitation and adhesion. Each sample was sent to the chip using a syringe pump at a constant flow rate of $1 \mathrm{ml} / \mathrm{h}$. After allowing the samples to flow through the polymeric CTC-chip, the tube was washed with PBS containing 5\% BSA once at $1 \mathrm{ml} / \mathrm{h}$ for $15 \mathrm{~min}$ to remove the suspended cells. The chip surface was then examined using an inverted fluorescent microscope (CKX41) equipped with a digital video camera (HDR-CX535; Sony) during the flow test. In this study, three types of polymeric CTC-chips were used to assess the capture efficiency with PBS and blood suspensions: i) No antibody treatment (non-treated chip); ii) a goat anti-mouse IgG antibody solitary coating (IgG-chip); and iii) a primary coating of goat anti-mouse IgG antibody and a secondary coating of mouse anti-human EpCAM antibody (EpCAM-chip). Notably, the flow test was repeated three to four times for the two suspensions using each of the three types of chips.

Thus, the number of cells remaining in the chip after the flow test $(\mathrm{Nr})$ was determined. The number of cells that passed through the chip inlet $(\mathrm{Np})$ had been evaluated before the test based on the cell concentration in ea43ch suspension. The cell-capture efficiency, defined as $\mathrm{Nr} / \mathrm{Np}$, was evaluated (32) for each test.

Characteristics of patients and volunteers. We enrolled 13 patients (age range, 59-77 years; men, 9; women, 4) with stages II-IV (UICC classification) colorectal cancer (37) and 2 healthy volunteers (control group), without detectable cancer or serious diseases, in the Department of Coloproctological Surgery, Juntendo University Hospital (Tokyo), from August 2015 to March 2016 (Table I). Histological features and differentiation grades of cancer tissue samples were evaluated in the Department of Diagnostic Pathology of the Juntendo University Hospital, according to JSCCR classification (38): Each patient was classified into the following categories: well-differentiated tubular adenocarcinoma (tub1), intermediately differentiated tubular adenocarcinoma (tub2), or poorly differentiated adenocarcinoma (por). In addition, CEA and CA19-9 levels in blood samples drawn from the participants before receiving any cancer treatment were evaluated. In this study, a value was considered 'positive' when higher than the set conventional cut-off values $(5.0 \mathrm{ng} / \mathrm{ml}$ for CEA and $37.0 \mathrm{U} / \mathrm{ml}$ for CA19-9) (39-41). This study was conducted in accordance with the Declaration of Helsinki and was approved by the Ethics Committee of Juntendo University (cat. no. 2015036). Furthermore, written informed consent was obtained from all participants after adequate counseling using written documents that described the research aim and any possible risks involved. 


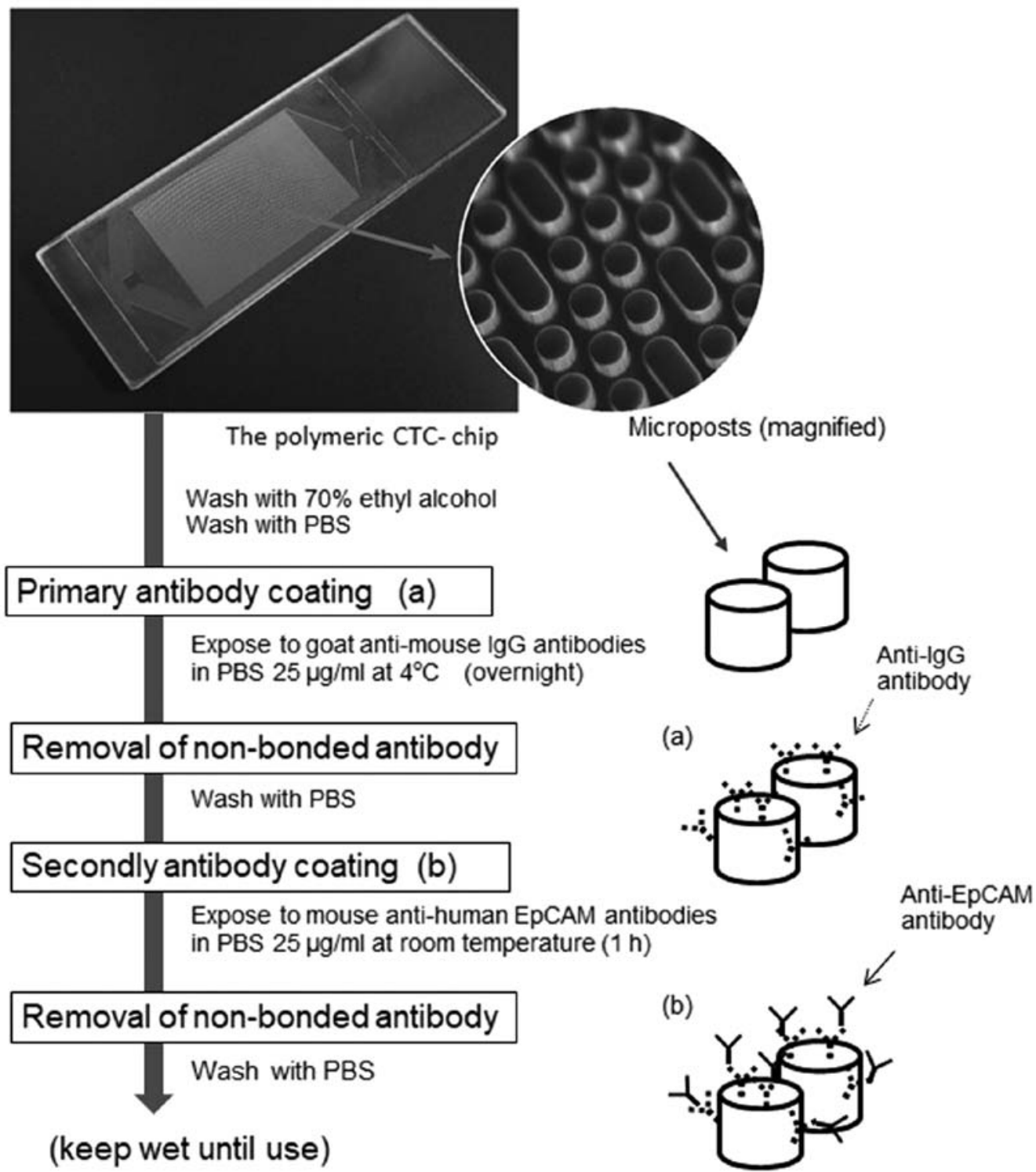

Figure 1. Process outline of antibody coating on the polymeric CTC-chip. The diameter of smaller microposts is $100 \mu \mathrm{m}$. CTC, circulating tumor cell.

Detection of CTCs from blood samples. Using a vacuum blood collection tube containing EDTA, $2 \mathrm{ml}$ of blood samples were drawn from all patients one day preoperatively. In patients with stages II and III cancer, blood samples were obtained again 6 days postoperatively. The blood samples were then placed in the polymeric CTC-chip coated with both goat anti-mouse IgG antibodies and mouse anti-human EpCAM antibodies at a flow rate of $1 \mathrm{ml} / \mathrm{h}$ for $1 \mathrm{~h}$, as previously described. After setting the blood samples, the chip was washed with PBS containing $5 \% \mathrm{BSA}$ at a flow rate of $2 \mathrm{ml} / \mathrm{h}$ for $30 \mathrm{~min}$ to remove the blood cell constituents that were nonspecifically combined with the chip. After using a $15 \%$ formaldehyde to anchor the cells, the chip was washed with $0.1 \%$ Triton X-100. Then, the aqueous antibody solution was successively introduced into the chip.

The FDA-approved technique to detect CTCs relies on the use of antibodies that target EpCAM, followed by cytokeratin $(\mathrm{CK})$ and CD45 staining, to confirm the epithelial phenotype (42). In the present study, fluorescein isothiocyanate (FITC)-conjugated anti-mouse CK $8+18$ (207) antibodies (ab190366; Abcam Plc, Cambridge, UK; $5 \mu \mathrm{l}: 50 \mu \mathrm{g} / \mathrm{ml}$ ) and Alexa Fluor ${ }^{\circledR}$ 594-conjugated anti-mouse CD45 antibodies (cat. no. 103144; BioLegend; $5 \mu \mathrm{l}: 50 \mu \mathrm{g} / \mathrm{ml}$ ) were used to differentiate epithelial adenocarcinoma cells and leukocytes. Diamidino-2-phenylindole dihydrochloride (DAPI; $20 \mu \mathrm{l}$ : $1.5 \mu \mathrm{g} / \mathrm{ml}$ ), a nuclear staining reagent, was also used to evaluate the presence/absence of cell nuclei. A cell was defined as to contain CTC when it was positive for both DAPI and CK but negative for CD45. Furthermore, CTCs remaining on the chip were observed and counted with images obtained using the inverted fluorescence microscope (CKX41).

Statistical analyses. The effects of antibody treatments (none, IgG, and IgG + EpCAM) of the polymeric CTC-chips on the cell-capture efficiencies were examined using an analysis of variance (ANOVA) after the angular transformation on the cell-capture efficiency defined as $\mathrm{Nr} / \mathrm{Np}$ (the captured and numbers of cells that passed through the chip), as previously described in both PBS and blood suspensions. Using Welch's two-sample t-test, effects of the polymeric CTC-chip 


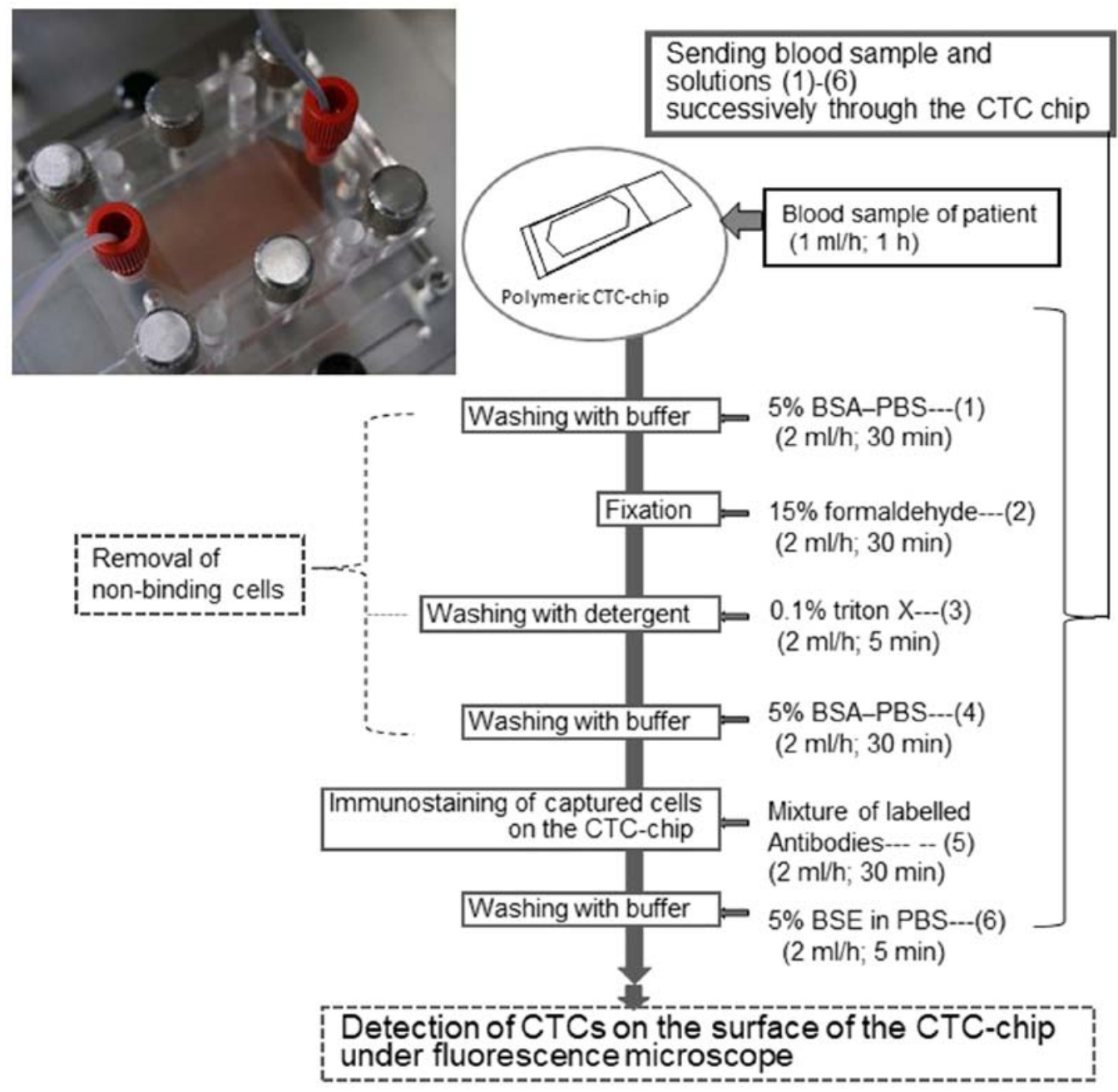

Figure 2. The workflow of CTC detection using the polymeric CTC-chip. The mixture of labelled antibodies (5) consist of FITC conjugated anti-mouse CK $8+18$ antibodies $(5 \mu \mathrm{l}: 50 \mu \mathrm{g} / \mathrm{ml})$, Alexa Fluor ${ }^{\circledR} 594$-conjugated anti-mouse CD45 antibodies (5 $\left.\mu \mathrm{l}: 50 \mu \mathrm{g} / \mathrm{ml}\right)$ and DAPI $(20 \mu \mathrm{l}: 1.5 \mu \mathrm{g} / \mathrm{ml})$. Upper left image: Top view of the polymeric CTC-chip connected with tubes sending a blood sample. CTC, circulating tumor cell.

treatment on capture efficiency were assessed based on the difference between the average cell-capture efficiency values and the angular transformation between two different treatments: No treatment, IgG-chip; no treatment, EpCAM-chip; and IgG-chip, EpCAM-chip (in both PBS and blood suspensions). Welch's t-test was also used to evaluate differences in the number of CTCs detected in blood samples obtained from patients with stages II-III and IV cancer. The paired t-test was used to determine the difference in numbers of CTC $/ \mathrm{ml}$ between blood samples pre- and postoperatively in patients with stages II-III cancer. Moreover, the Fisher exact test was used to compare the rates of patients detected with CTCs and those positive for CEA and CA19-9 tests. All statistical analyses were performed using the R software (v.3.2.5) (43).

\section{Results}

EpCAM expression of HCT116. The EpCAM expression in HCT116 cells was evaluated with flow cytometry using anti-EpCAM antibodies, showing that $97.3 \%$ of HCT116 cells were positive for EpCAM (Fig. 3). The immunofluorescence staining suggested that EpCAM was localized on the cell surface (Fig. 4).

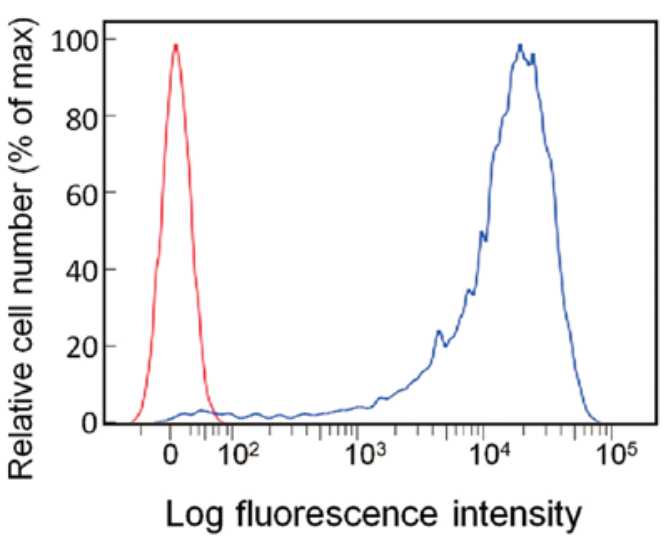

Figure 3. EpCAM expression in a colorectal cancer cell line measured using flow cytometry. The blue line indicates HCT116 cells stained with the PE/Cy7-conjugated anti-EpCAM antibodies. The red line indicates HCT116 cells without immunostaining. The $\mathrm{x}$-axis shows logarithmic fluorescence intensity. The $y$-axis shows relative cell numbers (the percentage for the maximum counts). EpCAM, epithelial cell-adhesion molecule.

Capture efficiency of the polymeric CTC-chip covered with antibodies. Capturing efficiencies of colorectal cancer cells spiked in PBS and blood suspensions were tested using the 
Table I. Patient characteristics with detected number of CTCs and CEA and CA19-9 values.

\begin{tabular}{|c|c|c|c|c|c|c|c|c|c|c|}
\hline \multirow[b]{2}{*}{ Patent no. } & \multirow[b]{2}{*}{ Age } & \multirow[b]{2}{*}{ Sex } & \multirow[b]{2}{*}{ Site } & \multirow[b]{2}{*}{$\begin{array}{l}\text { Histologic } \\
\text { features }\end{array}$} & \multirow[b]{2}{*}{ TNM classification } & \multirow[b]{2}{*}{ Stage } & \multicolumn{2}{|c|}{ CTCs (number/ml) } & \multirow[b]{2}{*}{$\begin{array}{l}\text { CEA } \\
(\mathrm{ng} / \mathrm{ml})\end{array}$} & \multirow[b]{2}{*}{$\begin{array}{l}\text { CA 19-9 } \\
(\mathrm{U} / \mathrm{ml})\end{array}$} \\
\hline & & & & & & & $\begin{array}{l}\text { Before } \\
\text { surgery }\end{array}$ & $\begin{array}{c}\text { After } \\
\text { surgery }\end{array}$ & & \\
\hline 1 & 74 & M & A & tub2 & T3 N0 M0 & II A & 1 & 2 & 7.9 & 37 \\
\hline 2 & 77 & $\mathrm{~F}$ & $\mathrm{D}$ & tub2 & T4a N0 M0 & II B & 6 & 2 & 6.8 & 7 \\
\hline 3 & 76 & $\mathrm{M}$ & $\mathrm{Rb}$ & tub2 & T3 N0 M0 & II A & 2 & 0 & 2.9 & 23 \\
\hline 4 & 77 & M & $\mathrm{S}$ & tub1 & T4b N0 M0 & II C & 4 & 1 & 4.9 & 34 \\
\hline 5 & 66 & $\mathrm{~F}$ & $\mathrm{C}$ & tub2 & T3 N1b M0 & III B & 1 & 0 & 23.6 & 24 \\
\hline 6 & 59 & M & $\mathrm{Rb}$ & tub2 & T3 N2b M0 & III C & 6 & 3 & 3.5 & 8 \\
\hline 7 & 70 & M & RS & tub2 & T3 N1b M1a (H2) & IVA & 12 & & 387.7 & 94 \\
\hline 8 & 72 & M & A & tub2 & T3 N0 M1a (H1) & IVA & 7 & & 14.3 & 21 \\
\hline 9 & 74 & M & RS & tub1 & T3 N2b M1a (LYM) & IVA & 18 & & 12.8 & 27 \\
\hline 10 & 67 & M & $\mathrm{S}$ & tub1 & T4b N2a M1a (LYM) & IVA & 5 & & 34.8 & 6 \\
\hline 11 & 77 & $\mathrm{~F}$ & A & tub2 & T4a N2a M1a (H2) & IVA & 2 & & 15.8 & 20 \\
\hline 12 & 61 & $\mathrm{~F}$ & A & tub2 & T3 N2b M1b (H1 PUL1) & IVB & 5 & & 7.6 & 6 \\
\hline 13 & 71 & M & $\mathrm{Ra}$ & por & T3 N1a M1a (H1) & IVA & 0 & & 1.4 & 6 \\
\hline
\end{tabular}

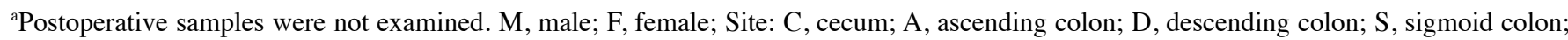
RS, rectosigmoid; upper R, upper rectum; lower R, lower rectum; tub, tubular adenocarcinoma; tub1, well differentiated; tub2, intermediately differentiated; por, poorly differentiated adenocarcinoma; TNM, tumor node metastasis; CTCs, circulating tumor cells; CEA, carcinoembryonic antigen; CA19-9, carbohydrate antigen 19-9.

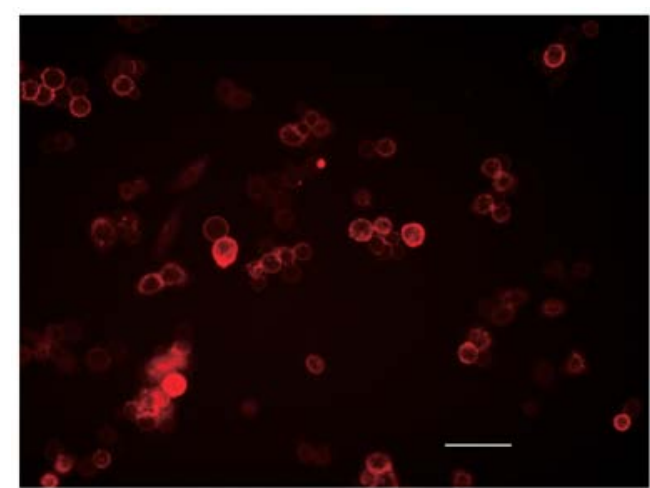

Figure 4. Fluorescent image of HCT116 cells stained with Alexa Fluor ${ }^{\circledR}$ 594-conjugated anti-epithelial cell-adhesion molecule antibodies. Scale bar: $50 \mu \mathrm{m}$.

polymeric CTC-chip by conducting three different treatments: i) Primarily coated with goat anti-mouse $\operatorname{IgG}$ antibodies and secondarily coated with mouse anti-human EpCAM antibodies, 'EpCAM-chip'; ii) coated only with goat anti-mouse IgG antibodies, 'IgG-chip'; or iii) no antibody treatment, 'non-treated chip.' Each suspension sample was set on the chip using a syringe pump at $1 \mathrm{ml} / \mathrm{h}$ for $1 \mathrm{~h}$. We determined that $1,109.4 \pm 392.8$ (average number \pm SD) cells in the PBS suspension and 1,160.8 \pm 119.9 cells in the blood suspension passed through the chip inlet during the suspension sending period. In the PBS suspension, capture efficiencies were $0.909 \pm 0.053$ (average rate $\pm \mathrm{SD}$ ) for the EpCAM-chip $(n=4), 0.060 \pm 0.010$ for the IgG-chip $(n=3)$, and $0.066 \pm 0.007$ for the non-treated chip ( $n=3$; Fig. 5), whereas in the blood suspension, the efficiencies were $0.650 \pm 0.064$ for the EpCAM-chip $(n=4), 0.066 \pm 0.016$ for

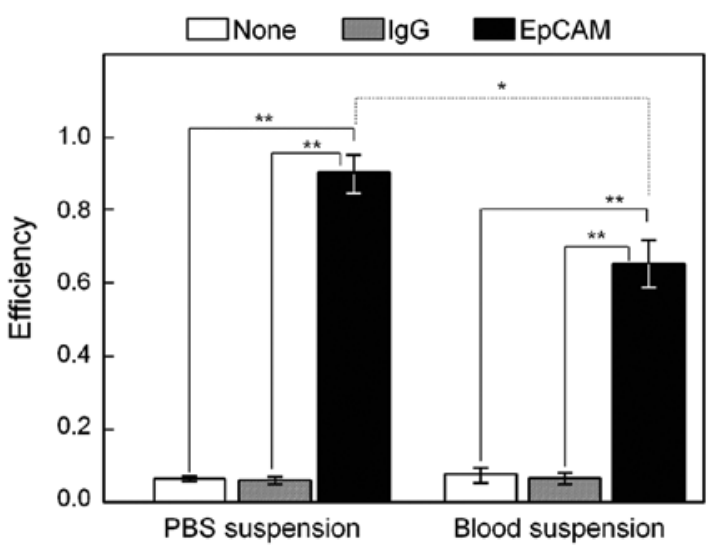

Figure 5. The capture efficiency of polymeric CTC-chip measured with PBS and whole blood suspensions of colorectal cancer cells (HCT116). Treatments of the polymeric CTC-chip: 'None' for no treatment chip (non-treated chip; $\mathrm{n}=3$ ), IgG for coated only with goat anti-mouse IgG antibodies (IgG-chip; $\mathrm{n}=3$ ), and EpCAM for primary coating with goat anti-mouse IgG antibodies and secondary coating with mouse anti-human EpCAM antibodies (EpCAM-chip; $\mathrm{n}=4$ ). Bar: standard deviation. ${ }^{*} \mathrm{P}<0.01$ and ${ }^{* *} \mathrm{P}<0.001$ as indicated. CTC, circulating tumor cell; EpCAM, epithelial cell-adhesion molecule.

the IgG-chip ( $n=3)$, and $0.077 \pm 0.002$ for the non-treated chip ( $n=3$; Fig. 5)

Significant differences in the cell-capture efficiency were determined after the angular transformation among the three chip treatments in the PBS $\left(\mathrm{P}=7.610 \times 10^{-8}\right)$ and blood $\left(\mathrm{P}=3.336 \times 10^{-7}\right)$ suspensions using ANOVA. In the PBS suspension, the capture efficiency values after an angular transformation assessed using Welch's t-test were significantly higher in the EpCAM-chip than those in the non-treated chip 
A

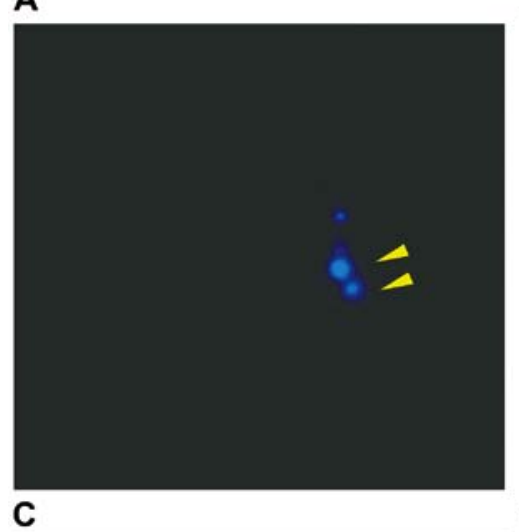

B

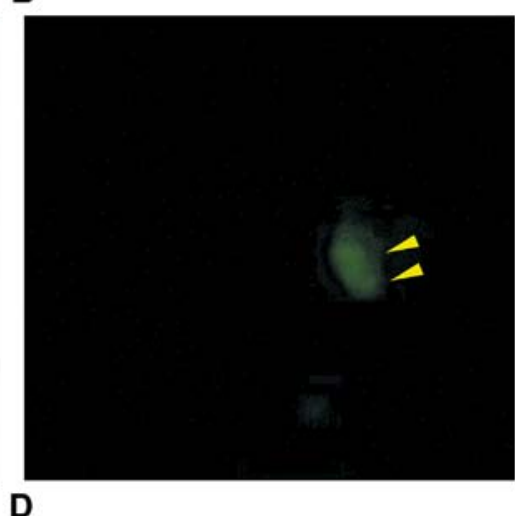

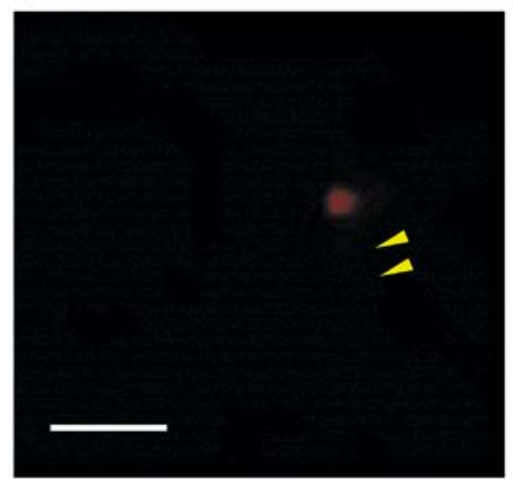

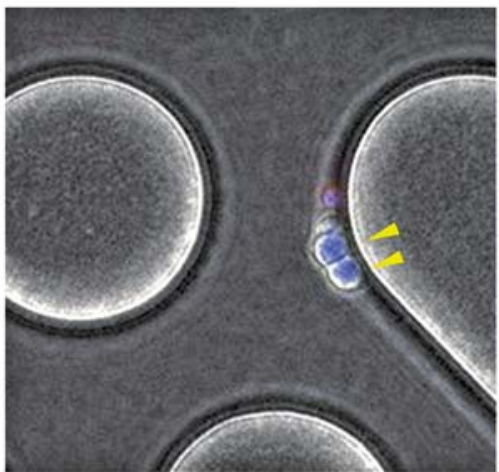

Figure 6. CTC in a blood sample of patient with colorectal cancer captured on the polymeric CTC-chip. Immunofluorescent image of cells on the chip for (A) DAPI (blue), (B) cytokeratin (green), (C) CD45 (red) and (D) merged, respectively. Cells positive for DAPI and cytokeratin staining but negative for CD45 were regarded as CTCs. Yellow arrows indicate CTCs detected on the CTC-chip. Scale bar, $50 \mu \mathrm{m}$. These images were taken using a camera built in BZ-X700 microscope using samples from patient no. 12 as presented in Table I. CTC, circulating tumor cell; DAPI, diamidino-2-phenylindole dihydrochloride.

$\left(\mathrm{P}=1.077 \times 10^{-4}, d f=3.220\right)$ and the $\mathrm{IgG}-\operatorname{chip}\left(\mathrm{P}=6.994 \times 10^{-5}\right.$ $d f=3.426)$. In addition, values in the non-treated chip did not differ from those in the IgG-chip $(\mathrm{P}=0.4384, d f=3.617)$. A similar tendency in the blood suspension was observed, showing that capture efficiency values after an angular transformation two-tailed Welch's t-test were significantly higher in the EpCAM-chip than those in the non-treated chip $\left(\mathrm{P}=2.647 \times 10^{-4}, d f=3.028\right)$ and $\mathrm{IgG}$-chip $\left(\mathrm{P}=2.180 \times 10^{-5}\right.$, $d f=4.561)$. Values in the non-treated chip did not differ from those in the $\operatorname{IgG}$-chip $(\mathrm{P}=0.3794, d f=2.057)$. Furthermore, the capture efficiency of the EpCAM-chip was significantly higher in the PBS suspension than that in the blood suspension $(\mathrm{P}=0.001071, d f=5.643)$.

Detection of CTCs in blood samples of patients with colorectal cancer and healthy volunteers. CTCs in the preoperative peripheral blood samples of 13 patients with stage II-IV colorectal cancer were enumerated on the chip (Figs. 6 and 7, Table I). The mean number of CTCs/ml in patients with stages II and III cancers $(3.3 \pm 2.3, n=6)$ tended to be lower than those with stage IV, with near-marginal significance (7.0 $\pm 6.2, n=7$; $t=1.4563, \mathrm{P}=0.0919$, one-tailed Welch's t-test). No CTCs were detected in one patient with stage IV cancer, with histological features defined as poorly differentiated adenocarcinoma (por), which was different from all other cases of well or moderately differentiated tubular adenocarcinoma (tub1 or tub2).

After excluding this patient, the mean number of CTCs $/ \mathrm{ml}$ associated with stage IV cancer $(8.2 \pm 5.8, n=6)$ tended to be higher than those with stages II and III cancer $(3.3 \pm 2.3, n=6)$, with difference that is close to being statistically significant ( $t=1.8806, \mathrm{P}=0.0524$, one-tailed Welch's $\mathrm{t}$-test $)$.

The number of CTC/ml in blood samples postoperatively (mean \pm SD: $1.3 \pm 1.2$ ) was significantly lower than that preoperatively $(3.3 \pm 2.3)$ in patients with stages II and III cancers $(n=6 ; t=2.7386, \mathrm{P}=0.0204$, one-tailed paired $\mathrm{t}$-test). In addition, no CTCs were detected in two healthy volunteer blood samples on polymeric CTC-chips.

The sensitivity of CTC detection using the polymeric CTC-chip compared with conventional biomarkers. The detection rate of CTCs was compared with that of positive rates detected using cancer markers. Nine patients had CEA or CA19-9 levels of higher than the cut-off values (CEA, $5.0 \mathrm{ng} / \mathrm{ml}$; CA19-9, $37.0 \mathrm{U} / \mathrm{ml}$ ) (Table I; Fig. 7). At least one CTC (per ml) was detected in 12 of 13 patients, whereas the CEA and CA19-9 levels were positive, i.e., above the cut-off values, in nine and two patients, respectively. For all cancer stages (II-IV), a significant difference was observed between the positivity rate from CTC detection and that from two biomarkers $(\mathrm{P}=0.0002251$ according to the $3 \times 2$ two-sided Fisher's exact test). In addition, the detection rate of CTCs in all patients was higher than that of CA19-9 $(\mathrm{P}=0.0002127$, Fisher's exact test) but not significantly higher than that of CEA $(\mathrm{P}=0.3217)$. These two conventional markers exhibited negative levels in the patient (no. 13 in Fig. 7) in whom no CTCs were detected. In all six patients with stage IV cancer (except for no. 13), both CTC and CEA values were positive, whereas the CA19-9 value was positive in only one patient. Although CTCs were 


\begin{tabular}{|c|c|c|c|c|c|c|c|c|c|c|c|c|c|c|c|c|}
\hline Stage & \multicolumn{4}{|c|}{ II } & \multicolumn{2}{|c|}{ III } & \multicolumn{7}{|c|}{ IV } & \multicolumn{3}{|c|}{$\%$ positive } \\
\hline Patient No. & 1 & 2 & 3 & 4 & 5 & 6 & 7 & 8 & 9 & 10 & 11 & 12 & 13 & II,III & IV & II,III,IV \\
\hline CTCs & & & & & & & & & & & & & & 100 & 86 & 92 \\
\hline CEA & & & & & & & & & & & & & & 50 & 86 & 69 \\
\hline CA19-9 & & & & & & & & & & & & & & 17 & 14 & 15 \\
\hline
\end{tabular}

Figure 7. CTC detection using the polymeric CTC-chip and based on the positivity of CEA and CA19-9 in blood samples of patients with colorectal cancer. Shaded boxes indicated a positive case with at least one or more CTCs detected or CEA and CA19-9 values higher than the respective cut-off values (5.0 ng/ml and $37.0 \mathrm{U} / \mathrm{ml}$ ). CTC, circulating tumor cell; CEA, carcinoembryonic antigen; CA19-9, carbohydrate antigen 19-9 test.

detected in all six patients with stages II and III cancer, CEA and CA19-9 values were positive in only two and one, respectively, of the four patients with stage II cancer, and in one and no patient, respectively, in two patients with stage III cancer.

\section{Discussion}

Capturing device development is expected to make CTCs a sensitive clinical biomarker to diagnose and predict the prognosis and treatment effects in cancers $(6,10,16)$. Using one of the new microfluidic devices to capture CTCs, the polymeric CTC-chip, CTCs were detected in the blood samples of most patients with colorectal cancer (12 of 13) who participated in this study. The CTC detection was confirmed as more sensitive than the two most common conventional marker tests for the diagnosis of colorectal cancer.

Newly developed devices for CTC detection are typically examined based on their capture efficiency of the target cancer cells $(15,16,44,45)$. In this study, the efficiency of the polymeric CTC-chip was first assessed on the colorectal cancer cell line, HCT116. The polymeric CTC-chip secondarily treated with anti-EpCAM antibodies exhibited a considerably high capture rate for HCT116 cells: $90 \%$ in the PBS suspension and 65\% in the whole blood suspension, which were comparable to or exceeded those reported in previous studies $(15,16,44,45)$. The efficiency seemed to exceed with those in existing devices. Nagrath et al (15) reported that the capture efficiency of the silicon microchip was $65-80 \%$ in the PBS suspension for several cell lines, which fit the prediction that HCT116, an EpCAM-positive cell line, could be captured with the polymeric CTC-chip treated with the anti-EpCAM antibody. However, 5-7\% of CTCs were captured using the chip without the anti-EpCAM antibody treatment, demonstrating that the chip trapped some cells with nonspecific bonds.

The number of CTCs $/ \mathrm{ml}$ tended to be higher in patients with stage IV than those with stages II and III cancers. Thus, CTC concentration seemed to increase with cancer state progression. Moreover, the number of CTCs $/ \mathrm{ml}$ in patients with stages II and III cancers postoperatively became lower than that preoperatively. These results suggested that the polymeric CTC-chip system could potentially be used to monitor disease progression and the treatment effects in patients with colorectal cancer.

CTCs are considered specific to cancer and are not detected in the peripheral blood of healthy individuals $(8,9)$. No CTCs were detected on the polymeric CTC-chip in the blood samples of two healthy volunteers. In this study, each patient was classified as 'CTC positive' when more than one CTCs were detected in the sample. The CTC positive rate in all stages tended to be higher than the positive rate obtained by blood tests with two conventional markers. CTCs were detected in all patients with stages II and III cancers (six patients), although three of them tested negative for CEA and five tested negative for CA19-9, suggesting that CTCs could be an effective cancer marker because of they are potentially detected in earlier stages than existing tumor markers.

The anti-EpCAM antibody binds with the EpCAM, which is typically expressed on epithelial cells $(3,5,11)$. However, the use of an anti-EpCAM antibody might not adequately capture EpCAM-negative cancer cells $(14,29,42,45)$. In this study, CTCs were not detected in the blood sample of one patient with stage IV cancer. In this case, CEA and CA19-9 values did not exceed the cut-off values despite cancer progression and distant metastasis. Histologically, the cancer tissue sample of this case was classified as poorly differentiated adenocarcinoma (por), whereas those of all other cases were classified as differentiated adenocarcinoma (tub1, 2). The cause of this failure of CTC detection remains unknown, although it may be related to the characteristics of the cancer tissue.

Other microfluidic devices treated with anti-PSMA, HER2, or epidermal growth factor receptor (EGFR) antibodies have detected CTCs in the blood samples of patients with prostate, breast, and lung cancers (45-47). Antibodies used in the secondary treatment on the polymeric CTC-chip are easily changeable. To take advantage of this feature, EpCAM-negative mesothelioma cells were captured using this polymeric CTC-chip treated with anti-podoplanin antibodies $(34,35)$. Using anti-EGFR antibodies on the surface of the polymeric CTC-chip, Ohnaga et al (36) recently reported a high capturing efficiency against several cell lines expressing EGFR.

Using alive CTCs alone, the expression level of oncogenes that are assumed to be related to colorectal cancer of a single cell or its offspring cells was analyzed. In circulating lung cancer cells collected from a microfluidic device, gene mutations in EGFR were detected (47). Future advancements of the CTC isolation technique in the polymeric CTC-chip will facilitate the evaluation of molecular markers.

This study validated the usefulness of CTC detection in blood samples obtained from patients with colorectal cancer using the polymeric CTC-chip; nevertheless, the number of participants was limited. Further studies should be conducted with more patients, including those in earlier stages of the disease, to assess the sensitivity of the polymeric CTC-chip in diagnosing colorectal cancer. 


\section{Acknowledgements}

The authors would like to thank Dr Yu Okazawa and Dr Kosuke Mizukoshi (Department of Coloproctological Surgery, Juntendo University, Tokyo, Japan), for providing the colorectal cancer cell line.

\section{Funding}

The present study was supported by JSPS KAKENHI (grant nos. 16K08974 and 25460700) to YT, TO and HK and by the Takeda Science Foundation in 2014 for HK.

\section{Availability of data and materials}

The datasets used and/analyzed during the present study are available from the corresponding author on reasonable request.

\section{Authors' contributions}

HK designed the study and provided the overall guidance with the advice of KS. KK analyzed the clinical data with help and advice from KS and YT. TO prepared the polymeric CTC-chip and antibody treatment. $\mathrm{KK}$ and $\mathrm{MH}$ conducted the detection of CTCs with the assistance of TU. KK, MH, HK and MF performed statistical data analyses and preparation of figures. The manuscript was written by KK and MF with critical revision by $\mathrm{MH}, \mathrm{TO}, \mathrm{KS}$ and $\mathrm{HK}$. All authors have read and approved the final manuscript.

\section{Ethics approval and consent to participate}

The present study was approved by the Ethics Committee of the Juntendo University, School of Medicine (approval no. 2016047). All participants (patients and healthy volunteers) provided written informed consent before participation.

\section{Patient consent for publication}

All participants in this work (patients and healthy volunteers) provided written informed consent for the publication of this article.

\section{Competing interests}

The authors declare that they have no competing interests.

\section{References}

1. Bray F, Ferlay J, Soerjomataram I, Siegel RL, Torre LA and Jemal A: Global cancer statistics 2018: GLOBOCAN estimates of incidence and mortality worldwide for 36 cancers in 185 countries. CA Cancer J Clin 68: 394-424, 2018.

2. Locker GY, Hamilton S, Harris J, Jessup JM, Kemeny N, Macdonald JS, Somerfield MR, Hayes DF and Bast RC Jr; ASCO ASCO 2006 update of recommendations for the use of tumor markers in gastrointestinal cancer. J Clin Oncol 24: 5313-5327, 2006

3. Racila E, Euhus D, Weiss AJ, Rao C, McConnell J, Terstappen LW and Uhr JW: Detection and characterization of carcinoma cells in the blood. Proc Natl Acad Sci USA 95: 4589-4594, 1998.

4. Jacob K, Sollier C and Jabado N: Circulating tumor cells: Detection, molecular profiling and future prospects. Expert Rev Proteomics 4: 741-756, 2007.
5. Paterlini-Brechot $\mathrm{P}$ and Benali NL: Circulating tumor cells (CTC) detection: Clinical impact and future directions. Cancer Lett 253: 180-204, 2007.

6. Ignatiadis M, Lee M and Jeffrey SS: Circulating tumor cells and circulating tumor DNA: Challenges and opportunities on the path to clinical utility. Clin Cancer Res 21: 4786-4800, 2015.

7. Krivacic RT, Ladanyi A, Curry DN, Hsieh HB, Kuhn P, Bergsrud DE, Kepros JF, Barbera T, Ho MY, Chen LB, et al: A rare-cell detector for cancer. Proc Natl Acad Sci USA 101: 10501-10504, 2004.

8. Allard WJ, Matera J, Miller MC, Repollet M, Connelly MC, Rao C, Tibbe AG, Uhr JW and Terstappen LW: Tumor cells circulate in the peripheral blood of all major carcinomas but not in healthy subjects or patients with nonmalignant diseases. Clin Cancer Res 10: 6897-6904, 2004.

9. Sato N, Hayashi N, Imamura Y, Tanaka Y, Kinoshita K, Kurashige J, Saito S, Karashima R, Hirashima K, Nagai Y, et al: Usefulness of transcription-reverse transcription concerted reaction method for detecting circulating tumor cells in patients with colorectal cancer. Ann Surg Oncol 19: 2060-2065, 2012.

10. Giannopoulou L, Kasimir-Bauer S and Lianidou ES: Liquid biopsy in ovarian cancer: Recent advances on circulating tumor cells and circulating tumor DNA. Clin Chem Lab Med 56: 186-197, 2018.

11. Kasimir-Bauer S, Hoffmann O, Wallwiener D, Wallwiener D, Kimmig R and Fehm T: Expression of stem cell and epithelial-mesenchymal transition markers in primary breast cancer patients with circulating tumor cells. Breast Cancer Res 14: R15, 2012.

12. Iinuma $\mathrm{H}$, Okinaga $\mathrm{K}$, Egami $\mathrm{H}$, Mimori $\mathrm{K}$, Hayashi $\mathrm{N}$, Nishida K, Adachi M, Mori M and Sasako M: Usefulness and clinical significance of quantitative real-time RT-PCR to detect isolated tumor cells in the peripheral blood and tumor drainage blood of patients with colorectal cancer. Int J Oncol 28: 297-306, 2006.

13. Iinuma H, Watanabe T, Mimori K, Adachi M, Hayashi N, Tamura J, Matsuda K, Fukushima R, Okinaga K, Sasako M and Mori M: Clinical significance of circulating tumor cells, including cancer stem-like cells, in peripheral blood for recurrence and prognosis in patients with Dukes' stage B and C colorectal cancer. J Clin Oncol 29: 1547-1555, 2011.

14. Gorges TM, Tinhofer I, Drosch M, Röse L, Zollner TM, Krahn T and Ahsen O: Circulating tumour cells escape from EpCAM-based detection due to epithelial-to-mesenchymal transition. BMC Cancer 12: 178, 2012.

15. Nagrath S, Sequist LV, Maheswaran S, Bell DW, Irimia D, Ulkus L, Smith MR, Kwak EL, Digumarthy S, Muzikansky A, et al: Isolation of rare circulating tumour cells in cancer patients by microchip technology. Nature 450: 1235-1239, 2007.

16. Ankeny JS, Court CM, Hou S, Li Q, Song M, Wu D, Chen JF, Lee T, Lin M, Sho S, et al: Circulating tumour cells as a biomarker for diagnosis and staging in pancreatic cancer. Brit J Cancer 114: 1367-1375, 2016.

17. Veridex, LLC: 510(k) Summary. CellSearch ${ }^{\mathrm{TM}}$ circulating tumor cell kit, premarket notification-expanded indications for UseColorectal. Nov 20, 2007. https://www.accessdata.fda. gov/cdrh_docs/pdf7/k071729.pdf. Accessed November 12, 2018.

18. Veridex, LLC: 510 (k) Summary. CellSearch ${ }^{\mathrm{TM}}$ circulating tumor cell kit premarket notification-expanded indications for use-metastatic prostate cancer. Feb 27, 2008. https://www.accessdata.fda. gov/cdrh_docs/pdf7/K073338.pdf. Accessed November 13, 2008.

19. Cristofanilli M, Budd GT, Ellis MJ, Stopeck A, Matera J, Miller MC, Reuben JM, Doyle GV, Allard WJ, Terstappen LW and Hayes DF: Circulating tumor cells, disease progression, and survival in metastatic breast cancer. N Engl J Med 351: 781-791, 2004.

20. Cristofanilli M, Hayes DF, Budd GT, Ellis MJ, Stopeck A, Reuben JM, Doyle GV, Matera J, Allard WJ, Miller MC, et al: Circulating tumor cells: A novel prognostic factor for newly diagnosed metastatic breast cancer. J Clin Oncol 23: 1420-1430, 2005.

21. Cohen SJ, Punt CJ, Iannotti N, Saidman BH, Sabbath KD, Gabrail NY, Picus J, Morse MA, Mitchell E, Miller MC, et al: Relationship of circulating tumor cells to tumor response, progression-free survival, and overall survival in patients with metastatic colorectal cancer. J Clin Oncol 26: 3213-3221, 2008.

22. De Bono JS, Scher HI, Montgomery RB, Parker C, Miller MC, Tissing H, Doyle GV, Terstappen LW, Pienta KJ and Raghavan D: Circulating tumor cells predict survival benefit from treatment in metastatic castration-resistant prostate cancer. Clin Cancer Res 14: 6302-6309, 2008. 
23. Miller MC, Doyle GV and Terstappen LW: Significance of circulating tumor cells detected by the CellSearch system in patients with metastatic breast colorectal and prostate cancer. J Oncol 2010: 617421, 2010.

24. Lowes LE, Hedley BD, Keeney M and Allan AL: User-defined protein marker assay development for characterization of circulating tumor cells using the CellSearch ${ }^{\circledR}$ system. Cytometry A 81: 983-995, 2012.

25. Reeh M, Effenberger KE, Koenig AM, Riethdorf S, Eichstädt D, Vettorazzi E, Uzunoglu FG, Vashist YK, Izbicki JR, Pantel K and Bockhorn M: Circulating tumor cells as a biomarker for preoperative prognostic staging in patients with esophageal cancer. Ann Surg 261: 1124-1130, 2015.

26. Sato N, Hayashi N, Imamura Yu, Tanaka Y, Kinoshita K, Kurashige J, Saito S, Karashima R, Hirashima K, Nagai Y, et al: Usefulness of transcription-reverse transcription concerted reaction method for detecting circulating tumor cells in patients with colorectal cancer. Ann Surg Oncol 19: 2060-2065, 2012.

27. Viswanath B, Kim S and Lee K: Recent insights into nanotechnology development for detection and treatment of colorectal cancer. Int J Nanomedicine 11: 2491-2504, 2016.

28. Guo W, Yang X, Sun YF, Shen MN, Ma XL, Wu J, Zhang CY, Zhou Y, Xu Y, Hu B, et al: Clinical significance of EpCAM mRNA-positive circulating tumor cells in hepatocellular carcinoma by an optimized negative enrichment and qRT-PCR-based platform. Clin Cancer Res 20: 4794-4805, 2014.

29. Kelley RK, Magbanua MJ, Butler TM, Collisson EA, Hwang J, Sidiropoulos N, Evason K, McWhirter RM, Hameed B, Wayne EM, et al: Circulating tumor cells in hepatocellular carcinoma: A pilot study of detection, enumeration, and next-generation sequencing in cases and controls. BMC Cancer 15: 206, 2015.

30. Hiraiwa K, Takeuchi H, Hasegawa H, Saikawa Y, Suda K, Ando T, Kumagai K, Irino T, Yoshikawa T, Matsuda S, et al: Clinical significance of circulating tumor cells in blood from patients with gastrointestinal cancers. Ann Surg Oncol 15: 3092-3100, 2008.

31. Sequist LV, Nagrath S, Toner M, Haber DA and Lynch TJ: The CTC-chip: An exciting new tool to detect circulating tumor cells in lung cancer patients. J Thorac Oncol 4: 281-283, 2009.

32. Ohnaga T, Shimada Y, Moriyama M, Kishi H, Obata T, Takata K, Okumura T, Nagata T Muraguchi A and Tsukada K: Polymeric microfluidic devices exhibiting sufficient capture of cancer cell line for isolation of circulating tumor cells. Biomed Microdevices 15: 611-616, 2013.

33. Ohnaga T, Shimada Y, Takata K, Obata T, Okumura T, Nagata T, Kishi H, Muraguchi A and Tsukada K: Capture of esophageal and breast cancer cells with polymeric microfluidic devices for CTC isolation. Mol Clin Oncol 4: 599-602, 2016.

34. Chikaishi Y, Yoneda K, Ohnaga T and Tanaka F: EpCAMindependent capture of circulating tumor cells with a 'universal CTC-chip'. Oncol Rep 37: 77-82, 2017.

35. Yoneda K, Chikaishi Y, Kuwata T, Ohnaga T and Tanaka F: Capture of mesothelioma cells with 'universal' CTC-chip. Oncol Lett 15: 2635-2640, 2018.
36. Ohnaga T, Takei Y, Nagata $\mathrm{T}$ and Shimada Y: Highly efficient capture of cancer cells expressing EGFR by microfluidic methods based on antigen-antibody association. Sci Rep 8: 12005, 2018.

37. Sobin LH, Gospodarowicz MK and Wittekind Ch (eds): TNM classification of malignant tumours, 7 th edition. Oxford, UK, Wiley-Blackwell, 2009.

38. Japanese Society for Cancer of the Colon and Rectum (JSCCR): Japanese classification of colorectal carcinoma. 2nd English edition, Kanehara and Co. Ltd, Tokyo, 2009.

39. Thomsen M, Skovlund E, Sorbye H, Bolstad N, Nustad KJ, Glimelius B, Pfeiffer P, Kure EH, Johansen JS, Tveit KM, et al: Prognostic role of carcinoembryonic antigen and carbohydrate antigen 19-9 in metastatic colorectal cancer: A BRAF-mutant subset with high CA 19-9 level and poor outcome. Br J Cancer 118: 1609-1616, 2018.

40. Stojkovic Lalosevic M, Stankovic S, Stojkovic M, Markovic V, Dimitrijevic I, Lalosevic J, Petrovic J, Brankovic M, Pavlovic Markovic A and Krivokapic Z: Can preoperative CEA and CA19-9 serum concentrations suggest metastatic disease in colorectal cancer patients? Hell J Nuc Med 20: 41-45, 2017.

41. Watanabe M, Takemasa I, Kaneko N, Yokoyama Y, Matsuo E, Iwasa S, Mori M, Matsuura N, Monden M and Nishimura O: Clinical significance of circulating galectins as colorectal cancer markers. Oncol Rep 25: 1217-1226, 2011.

42. Pecot CV, Bischoff FZ, Mayer JA, Wong KL, Pham T, Bottsford-Miller J, Stone RL, Lin YG, Jaladurgam P, Roh JW, et al: A novel platform for detection of CK+ and CK- CTCs. Cancer Discov 1: 580-586, 2011.

43. R Core Team: R: A language and environment for statistical computing. $R$ foundation for statistical computing, Vienna, Austria. URL https://www.R-project.org/, 2016.

44. Lu YT, Zhao L, Shen Q Garcia MA, Wu D, Hou S, Song M, Xu X, Ouyang WH, Ouyang WW, et al: NanoVelcro Chip for CTC enumeration in prostate cancer patients. Methods 64: 144-152, 2013.

45. Galletti G, Sung MS, Vahdat LT, Shah MA, Santana SM, Altavilla G, Kirby BJ and Giannakakou P: Isolation of breast cancer and gastric cancer circulating tumor cells by use of an anti HER2-based microfluidic device. Lab Chip 14: 147-156, 2014.

46. Gleghorn JP, Pratt ED, Denning D, Liu H, Bander NH, Tagawa ST, Nanus DM, Giannakakou PA and Kirby BJ: Capture of circulating tumor cells from whole blood of prostate cancer patients using geometrically enhanced differential immunocapture (GEDI) and a prostate-specific antibody. Lab Chip 10: 27-29, 2010.

47. Maheswaran S, Sequist LV, Nagrath S, Ulkus L, Brannigan B Collura CV, Inserra E, Diederichs S, Iafrate AJ, Bell DW, et al: Detection of mutations in EGFR in circulating lung-cancer cells. N Engl J Med 359: 366-377, 2008.

This work is licensed under a Creative Commons Attribution-NonCommercial-NoDerivatives 4.0 International (CC BY-NC-ND 4.0) License. 